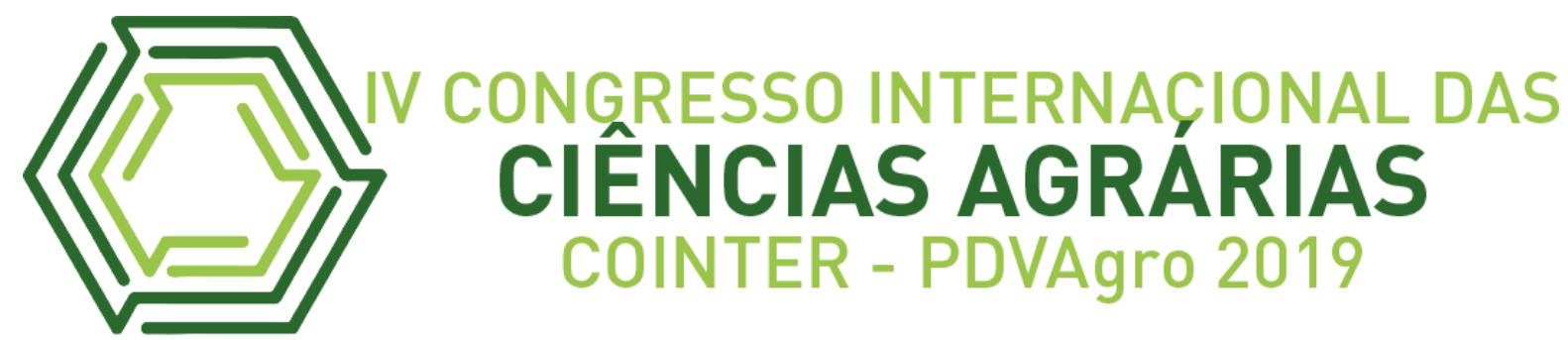

\title{
CARACTERIZAÇÃO FÍSICO-QUÍMICA DE FOLHA DE AMORA (Morus nigra L.) COM FINS DE DESENVOLVIMENTO DE PRODUTOS ENRIQUECIDOS
}

\section{CARACTERIZACIÓN FÍSICA Y QUÍMICA DE HOJA DE ZARZAMORA (Morus nigra L.) PARA FINES DE DESRROLLO DE LOS PRODUCTOS REQUIRIDOS}

\section{PHYSICOCHEMICAL CHARACTERIZATION OF BLACKBERRY LEAF (Morus nigra L.) FOR THE DEVELOPMENT OF ENRICHED PRODUCTS}

\author{
Apresentação: Comunicação Oral \\ Layra Catarina de Almeida Xavier ${ }^{1}$; Karla Rayana de Oliveira Silva²; Rafaele Cabral \\ Barbosa $^{3}$; Suzana Pedroza da Silva ${ }^{4}$
}

DOI: https://doi.org/10.31692/2526-7701.IVCOINTERPDVAgro.2019.0045

\begin{abstract}
Resumo
A amora (Morus nigra L.) é originária do continente Asiático, em relação ao Brasil pode-se dizer que a espécie nigra apresenta um crescimento satisfatório, ela possui 24 espécies com mais de 100 variedades conhecidas. A folha de amoreira é uma parte pouco consumida, mas que é rica nutricionalmente e é utilizada pela população com fins medicinais. Essa parte da planta pode ser utilizada como matéria-prima na produção de um novo alimento ou adicionada em alimentos já existentes, sendo uma alternativa para reaproveitá-la. Partes pouco consumida de plantas, vegetais e frutas como folhas e talos podem ser inseridas na alimentação, trazendo uma diversidade na alimentação e na dieta humana. O presente trabalho tem por objetivo a caracterização físico-química da folha de amora, com o intuito de verificar o seu potencial para o desenvolvimento de novos alimentos enriquecidos As análises efetuadas foram: umidade, cinzas, $\mathrm{pH}$, sólidos solúveis totais, acidez total titulável, atividade de água, açúcares redutores, colorimetria e lipídeos. As amostras de folhas de amora foram coletadas na Unidade Acadêmica de Garanhuns (UAG), da Universidade Federal Rural de Pernambuco (UFRPE). As análises foram realizadas em triplicata, seguindo as metodologias

\footnotetext{
${ }^{1}$ Engenharia de Alimentos, Universidade Federal Rural de Pernambuco - Unidade Acadêmica de Garanhuns, layracatarina@gmail.com.

${ }^{2}$ Engenharia de Alimentos, Universidade Federal Rural de Pernambuco - Unidade Acadêmica de Garanhuns, karla.rayana23@gmail.com.

${ }^{3}$ Engenharia de Alimentos, Universidade Federal Rural de Pernambuco - Unidade Acadêmica de Garanhuns, rafaelle100gbg@outlook.com.

${ }^{4}$ Professora Doutora em Engenharia Química pela Universidade Federal Rural de Pernambuco - Professora Adjunta II da Universidade Federal Rural de Pernambuco - Unidade Acadêmica de Garanhuns, suzpedroza@gmail.com.
} 
do Instituto Adolfo Lutz (2008). A folha de amora apresentou 0,0097\% de açúcares redutores, acidez de 0,4 $\pm 0,1 \mathrm{~g}$ de ácido cítrico/100 $\mathrm{g}$ de amostra, atividade de água de 0,976 $\pm 0,004$, teor de cinzas de 8,92 $\pm 0,40$, parâmetros $\mathrm{L}^{*}, \mathrm{a}^{*}$, $\mathrm{b}^{*}$ da análise de cor 14,4 $\pm 2,2,-1,3 \pm 3,2 \mathrm{e}$ $0,5 \pm 3,7$ respectivamente, lipídeos 5,36 $\pm 0,59 \%$, pH 6,86 $\pm 0,09$, teor de umidade 77,25 $\pm 2,68 \%$ e sólidos solúveis totais de $2,8 \pm 0,1{ }^{\circ}$ Brix. Com base na caracterização da folha de amora, é possível observar que a sua implementação na alimentação é viável, devido sua composição. A folha pode ser adicionada a algum produto já existente, enriquecendo-o, pois ela é rica em nutrientes e fornece ao seu consumidor uma refeição saudável e diversificada, além do mais é uma maneira de contribuir na redução do desperdício desta matéria-prima.

Palavras-Chave: Amora, enriquecimento, folha, Morus nigra L.

\section{Resumen}

La mora (Morus nigra L.) se origina en el continente asiático, en comparación con Brasil, se puede decir que la especie nigra presenta un crecimiento satisfactorio, tiene 24 especies con más de 100 variedades conocidas. La hoja de morera es una parte poco consumida, pero es rica en nutrientes y es utilizada por la población con fines medicinales. Esta parte de la planta puede usarse como materia prima en la producción de un nuevo alimento o agregarse a los alimentos existentes, siendo una alternativa para reutilizarla. Las partes subexpuestas de plantas, verduras y frutas, como hojas y tallos, se pueden insertar en la dieta, lo que aporta una diversidad en la dieta y en la dieta humana. El objetivo del presente trabajo es la caracterización fisicoquímica de la hoja de mora, con el fin de verificar su potencial para el desarrollo de nuevos alimentos enriquecidos. actividad del agua, reduciendo azúcares, colorimetría y lípidos. Se recogieron muestras de hojas de mora en la Unidad Académica Garanhuns (UAG) de la Universidad Federal Rural de Pernambuco (UFRPE). Los análisis se realizaron por triplicado, siguiendo las metodologías del Instituto Adolfo Lutz (2008). La hoja de mora tenía $0.0097 \%$ de azúcares reductores, acidez de $0.4 \pm 0.1 \mathrm{~g}$ de ácido cítrico / $100 \mathrm{~g}$ de muestra, actividad de agua $0.976 \pm 0.004$, contenido de cenizas $8.92 \pm 0,40$, parámetros $\mathrm{L}$ $*, \mathrm{a} *, \mathrm{~b} *$ de análisis de color $14.4 \pm 2.2,-1.3 \pm 3.2$ y $-0.5 \pm 3.7$ respectivamente, lípidos 5.36 $\pm 0.59 \%, \mathrm{pH} 6.86 \pm 0.09$, contenido de humedad $77.25 \pm 2.68 \%$ y sólidos solubles totales de $2.8 \pm 0.1^{\circ}$ Brix. En función de la caracterización de la hoja de mora, es posible observar que su implementación en el alimento es viable, debido a su composición. La hoja se puede agregar a un producto existente, enriqueciéndolo porque es rico en nutrientes y proporciona a sus consumidores una comida sana y diversificada, y también es una forma de ayudar a reducir el desperdicio de esta materia prima.

Palabras Clave: enriquecimento, hojas, Morus nigra L., zarzamora.

\footnotetext{
Abstract

The blackberry (Morus nigra L.) originates from the Asian continent, compared to Brazil it can be said that the species nigra presents a satisfactory growth, it has 24 species with more than 100 known varieties. Mulberry leaf is a little consumed part, but it is nutritionally rich and is used by the population for medicinal purposes. This part of the plant can be used as raw material in the production of a new food or added to existing foods, being an alternative to reuse it. Underexposed parts of plants, vegetables and fruits such as leaves and stems can be inserted into the diet, bringing a diversity in the diet and the human diet. The objective of the
} 
present work is the physicochemical characterization of the blackberry leaf, in order to verify its potential for the development of new enriched foods. The analyzes were: moisture, ash, $\mathrm{pH}$, total soluble solids, total titratable acidity. water activity, reducing sugars, colorimetry and lipids. Blackberry leaf samples were collected at the Garanhuns Academic Unit (UAG) of the Federal Rural University of Pernambuco (UFRPE). The analyzes were performed in triplicate, following the methodologies of the Adolfo Lutz Institute (2008). The blackberry leaf had $0.0097 \%$ reducing sugars, acidity of $0.4 \pm 0.1 \mathrm{~g}$ citric acid / $100 \mathrm{~g}$ sample, water activity $0.976 \pm 0.004$, ash content $8.92 \pm 0,40$, parameters $L^{*}, a *, b *$ of color analysis 14.4 $\pm 2.2,-1.3 \pm 3.2$ and $-0.5 \pm 3.7$ respectively, lipids $5.36 \pm 0.59 \%, \mathrm{pH} 6.86 \pm 0.09$, moisture content $77.25 \pm 2.68 \%$ and total soluble solids of $2.8 \pm 0.1^{\circ}$ Brix. Based on the characterization of the blackberry leaf, it is possible to observe that its implementation in the feed is viable, due to its composition. The leaf can be added to an existing product, enriching it because it is rich in nutrients and provides its consumer with a healthy and diversified meal, and is also a way to help reduce the waste of this raw material.

Keywords: blackberry, enrichment, leaf, Morus nigra L.

\section{Introdução}

O desperdício de alimentos é um problema nacional, e segundo a EMBRAPA (2009) cerca de 26 milhões de toneladas é desperdiçada ao ano, o que poderia alimentar cerca 35 milhões de pessoas. Uma alternativa para minimizar o destino indevido de matérias-primas vegetais é o aproveitamento integral de partes pouco usuais dos alimentos.

A folha de amora é uma parte pouco consumida, mas que é rica nutricionalmente e é utilizada pela população, principalmente na forma de chá para tratamento medicinal, especialmente de forma caseira, sem prescrição médica. Essa parte da amoreira pode ser estudada, explorada e utilizada na produção de um novo produto alimentício ou ainda adicionadas em alimentos já consumidos, enriquecendo e aumentando as possibilidades de adicioná-la à dieta. É uma alternativa viável para o reaproveitamento desta matéria-prima, criando receitas práticas e acessíveis, visando uma destinação diversificada, logo que a mesma já é utilizada na elaboração de produtos devido a seus efeitos benéficos à saúde.

Para a correta verificação dos benefícios em relação a seu poder nutricional e implementação desse alimento no cotidiano, é preciso ter conhecimento sobre a sua composição. Para isso realizou-se as análises físico-químicas, sendo elas: umidade, cinzas, $\mathrm{pH}$, sólidos solúveis totais (SST), acidez total titulável (ATT), atividade de água (Aw), açúcares redutores (AR), cor e lipídeos. O objetivo do presente trabalho foi realizar a caracterização físico-química da folha de amora com o intuito de utilizá-la como matéria- 
prima na elaboração de novos alimentos, a fim de melhorar sua composição nutricional e inovar na produção de alimentos.

\section{Fundamentação Teórica}

Em uma análise a cada 100 caixas de produtos agrícolas prontos para o consumo, cerca de 61 chega ao seu destino e, $60 \%$ do lixo urbano produzido é de origem alimentar (EMBRAPA, 2009). Estudos vêm sendo realizados nesta área a fim de demonstrar favorecimento do consumo desses produtos e inclusão na dieta. Dessa forma, as informações do valor nutricional dos alimentos originados da agricultura são escassas e sua utilização pequena, gerando baixo aproveitamento do alimento e desperdício de partes consumíveis (DAMIANI et al., 2011; SILVA \& RAMOS, 2009; VALENÇA \& SANTANA \& FREITAS, 2008).

Algumas partes pouco consumíveis de alguns vegetais e frutas como folhas, talos e cascas, que normalmente são descartadas e não consumidas, apresentam composição nutricional rica, sendo fontes de fibras e lipídeos (ROCHA et al., 2008). Essas partes podem ser utilizadas para enriquecer alimentos, diminuindo o desperdício e contribuindo com o meio ambiente. Com isso, adicionar essas partes em algum alimento ou produto já existente é uma boa alternativa de incluí-las na dieta humana.

A amora (Morus nigra L.) é originária do continente Asiático e no Brasil podemos dizer que a espécie 'nigra' apresenta um crescimento satisfatório, possuindo 24 espécies com mais de 100 variedades conhecidas, comumente encontradas em regiões de clima temperado. A amora é um alimento que possui diversos nutrientes que agrega valor nutricional, dentre eles vem se destacando os flavonoides, o qual é um pigmento com atividade antioxidante, que traz vários benefícios à saúde mediante sua inclusão na alimentação diária, sendo um deles a capacidade de atuar contra doenças cardiovasculares (ANTUNES, 2002). A amoreira possui frutos com conteúdo nutricional e valor econômico expressivos, dentre esses nutrientes a vitamina $\mathrm{C}$, água, carboidratos e minerais como potássio, zinco, cálcio, magnésio, cobre, entre outros (VIZZOTO, 2008).

Além da polpa, a folha da amora também é utilizada de forma medicinal pela população devido a seus benefícios à saúde tais como: ajuda no tratamento da diabetes, colesterol, problemas cardíacos e obesidade (ERCISLI \& ORHAN, 2007).

\section{Metodologia}


As folhas de amora foram coletadas no município de Garanhuns-PE, sendo retiradas de uma matriz situada na Unidade Acadêmica de Garanhuns (UAG) da Universidade Federal Rural de Pernambuco (UFRPE). As análises foram realizadas em triplicata, exceto a de açúcares redutores, que foi efetuada em duplicata, no laboratório de Análise de Alimentos, localizado na UAG/UFRPE. As folhas de amora foram lavadas com água corrente e dispostas sobre papel toalha até secagem completa. Posteriormente, foram realizadas as análises físicoquímicas para a caracterização de forma qualitativa e quantitativa da sua composição.

\section{Determinação de umidade e cinzas}

Para realizar o experimento e se obter resultados satisfatórios sem presença de contaminantes, foi realizada a devida lavagem dos cadinhos. Em seguida foram colocados em estufa à $105{ }^{\circ} \mathrm{C}$ por 1 hora. Após este procedimento foram colocados no dessecador e posteriormente pesados. Foram pesados em média 2,0288 g da amostra em cápsula de porcelana com três repetições. Para retirada de toda umidade foi necessário aproximadamente 18 h. A umidade pode ser obtida através da Equação 1 (INSTITUTO ADOLFO LUTZ, 2008).

Umidade $=\frac{100 * N}{P}(\%)$

Onde

$\mathrm{N}=\mathrm{n}^{\mathrm{o}}$ de gramas de umidade

$\mathrm{P}=\mathrm{n}^{\circ}$ de gramas de amostra

$\mathrm{O}$ teor de cinzas foi determinado através do método de secagem em mufla à $550{ }^{\circ} \mathrm{C}$. Os mesmos cadinhos utilizados para determinação de umidade foram usados para quantificação de cinzas, após 7 horas e 30 minutos na mufla. Os cadinhos foram retirados e mantidos em dessecador por 20 minutos para que resfriassem e então foram pesados. Para obter o teor de cinzas, utiliza-se a Equação 2 (INSTITUTO ADOLFO LUTZ, 2008) apresentada a seguir:

$$
\text { Cinzas }=\frac{100 * N}{P}(\%)
$$

Onde

$\mathrm{N}=\mathrm{n}^{\circ}$ de $\mathrm{g}$ de cinzas

$\mathrm{P}=\mathrm{n}^{\mathrm{o}}$ de $\mathrm{g}$ da amostra 
As folhas de amora foram cortadas e maceradas para que se realizasse uma pesagem de aproximadamente $5 \mathrm{~g}$ e adicionou-se $50 \mathrm{~mL}$ de água destilada para obtenção de uma homogeneização do material.

Para a acidez total titulável (ATT) da folha de amora foi usado $50 \mathrm{~mL}$ de hidróxido de sódio $(\mathrm{NaOH})$ como titulante $(0,1 \mathrm{M})$. Para ser titulado se fez uso de $1 \mathrm{~mL}$ da amostra, e 50 $\mathrm{mL}$ de água destilada, logo inseriu-se esta diluição a um erlenmyer de $125 \mathrm{~mL}$ realizando o procedimento. Para obter os resultados utilizou-se a Equação 3 (INSTITUTO ADOLFO LUTZ, 2008) descrita abaixo.

$\frac{V * f * 100}{P * C}=$ Acidez em solução molar por cento

Onde:

$\mathrm{V}=$ Numero de $\mathrm{mL}$ de Hidróxido de Sódio gasto

f = Fator de solução de Hidróxido de Sódio

$\mathrm{P}=$ Numero de gramas da amostra

$\mathrm{C}=$ Correção para $\mathrm{NaOH} 1 \mathrm{M}, 10$ para solução $\mathrm{NaOH}$ 0,1 M e 100 para $\mathrm{NaOH}$ 0,01 M.

Para análise de sólidos solúveis totais (SST) foi realizada uma filtração de uma alíquota do material previamente homogeneizada. Esta solução foi transferida para um béquer de $50 \mathrm{~mL}$. Com o auxílio de uma pipeta de Pasteur foi adicionada uma gota da amostra no centro do refratômetro observou-se a mudança da cor na escala diagramática obtendo os resultados.

Para as análises de potencial Hidrogeniônico $(\mathrm{pH})$ utilizou-se a medição em potenciômetro.

No experimento de atividade de água o material macerado foi separado em três recipientes plásticos e posteriormente inserida no AquaLab.

\section{Determinação dos Açúcares redutores e colorimetria}

As folhas de amora foram cortadas e maceradas. Utilizou-se o ácido 3,5dinitrosalicílico (DNS). Pesou-se aproximadamente 2 g de amostra diluída em $20 \mathrm{~mL}$ de água destilada. Separou-se 4 tubos de ensaio, onde em um dos tubos foi o branco adicionando-se $1 \mathrm{~mL}$ de DNS e $2 \mathrm{~mL}$ de água destilada e os outros três tubos continham $1 \mathrm{~mL}$ de DNS e $2 \mathrm{~mL}$ de amostra. Os tubos foram levados ao Banho Maria, previamente aquecido, por 5 minutos. Posteriormente, os tubos foram resfriados até atingir a temperatura ambiente e 
levados para análise no espectrofotômetro. Com os valores de absorbância e transmitância obtidos, foi construído um gráfico no Excel 2013 que representa o teor de açúcares redutores presente na amostra.

Para a análise de cor utilizou-se um colorímetro portátil manual Konica MINOLTA CR-10, que indica os parâmetros $\mathrm{L}^{*}$ (luminosidade), $\mathrm{a}^{*}$ (componente vermelho-verde) e b* (componente amarelo-azul). Antes de analisar a amostra, foi realizada a medição dos parâmetros preto e branco. Então, realizou-se o experimento em triplicata, usando as folhas de amora in natura, obtendo-se os parâmetros $\mathrm{L}^{*}, \mathrm{a}^{*}$ e b*.

\section{Determinação do teor de lipídeos}

A análise em questão foi realizada em duplicata. As folhas foram cortadas realizou-se a maceração com isto a amostra foi levada a estufa $\left(105{ }^{\circ} \mathrm{C}\right)$ até a secagem completa triturando-as ao final. Foi cortado em média 30-40 cm de barbante que foram pesados bem como o papel filtro. Pesou-se aproximadamente $1 \mathrm{~g}$ da amostra seca e a colocou-se em um cartucho no extrator tipo Soxhlet. Adicionou-se o hexano ao balão até pouco mais que a metade do mesmo. Ligou-se o equipamento e esperou-se a realização das 6 viragens, para completa extração. Após, a manta aquecedora foi desligada e aguardou-se atingir a temperatura ambiente.

O cartucho da amostra foi retirado do extrator e submetido à secagem completa em estufa a $105{ }^{\circ} \mathrm{C}$. Após 2 horas, foram colocadas no dessecador até que a temperatura ambiente foi atingida. Pesaram-se os cartuchos e realizou-se os cálculos para encontrar o teor de lipídeos presente na amostra, usando a Equação 4 e 5 (INSTITUTO ADOLFO LUTZ, 2008).

$E E=($ amostra + papel de filtro + barbante $)-$ cartucho após extração

$\%$ Lipídeos $=\frac{E E}{A S A} * 100$

Sendo:

$\mathrm{EE}=$ Massa de lipídeos em grama

ASA $=$ Massa da amostra em grama

\section{Resultados e Discussão}

Os resultados obtidos através da caracterização físico-química das folhas de amora estão apresentados na Tabela 1. 
Tabela 1: Análises físico-químicas da folha de amora (Morus nigra L.)

\begin{tabular}{cc}
\hline PARÂMETROS & MÉDIA \pm DESVIO \\
\hline AR (absorbância do DNS) & $2,869 \pm 0,00$ \\
ATT (g ácido cítrico /100g amostra) & $0,4 \pm 0,1$ \\
Aw & $0,976 \pm 0,004$ \\
Cinzas (\%) & $8,92 \pm 0,40$ \\
& Parâmetro $\mathrm{L}^{*}: 14,4 \pm 2,2$ \\
Colorimetria & Parâmetro a*: $-1,3 \pm 3,2$ \\
Lipídeos (\%) & Parâmetro $\mathrm{b}^{*}:-0,5 \pm 3,7$ \\
$\mathrm{pH}$ & $5,36 \pm 0,59$ \\
Umidade (\%) & $6,86 \pm 0,09$ \\
SST $\left({ }^{\circ}\right.$ Brix $)$ & $77,25 \pm 2,68$ \\
\end{tabular}

Fonte: Própria (2019)

A análise de açúcares redutores mostrou que a folha de amora apresenta baixo teor de açúcares redutores $0,0097 \%$ (TABELA 1). O resultado pode ser explicado devido à ocorrência da senescência, pois as folhas analisadas já estavam num período de maturação elevada. Nessa fase a taxa de fotossíntese cai, diminuindo o teor de açúcares redutores nas folhas. Durante as fases iniciais do crescimento das bagas, o alto teor de açúcares redutores nas folhas maduras, se deve à alta taxa de transporte de fotoassimilados necessários à produção de açúcares estruturais, como celulose, pectina e hemiceluloses. Há um grande acúmulo de frutose e glicose nas bagas durante a sua maturação. Esses autores ainda afirmam que a diminuição dos açúcares redutores foliares, após as bagas maduras ocorrer devido à menor demanda por açúcares do cacho (TAKAYANAGI \& YOKOTSUKA, 1997).

A folha de amora é um alimento que contém em sua composição um baixo teor de ácido como observado a partir da análise de acidez total titulável, que apresentou um resultado de 0,4 \pm 0,1 g de ácido cítrico em $100 \mathrm{~g}$ de amostra (TABELA 1). Esta análise fornece informações importantes em relação à conservação da amostra estudada, pois os processos de decomposição normalmente alteram a concentração dos íons de hidrogênio, e os ácidos orgânicos exercem influência no odor, cor, sabor, na conservação da qualidade e na 
estabilidade do alimento (ARGANDONA et al., 2017). Infere-se que as folhas de amora são resistentes a oxidação.

Ao analisar as amostras para quantificar a atividade de água das folhas de amora encontrou-se uma média de 0,976 (TABELA 1). A atividade de água (Aw) encontrada permite o entendimento que as folhas estão sujeitas a crescimento microbiano, visto que quanto maior a atividade de água no alimento, maior a susceptibilidade ao crescimento microbiano. Caso a atividade de água diminua ocorrerá então a possibilidade de conservação do produto, podemos dizer que essa etapa desempenha um papel importante no desenvolvimento de algumas características tais como sabor, textura e cor, pois ocorrem várias reações químicas e modificações em sua estrutura (TERRA, FREITAS e CICHOSKI, 2007). O crescimento de bactérias patogênicas e outros microrganismos que afetam negativamente os alimentos se desenvolvem rapidamente na faixa de atividade de água entre 0,986 a 0,99 (TERRA, FREITAS e CICHOSKI, 2007), compreendendo-se que as amostras de folha de amora estão bem próximas da faixa de crescimento desses microrganismos, mas por ter Aw inferior elas não são susceptíveis ao ataque destes seres.

A quantidade de cinzas encontrada nas folhas de amora foi de 8,92 $\pm 0,40 \%$, (TABELA 1), revelando que a mesma apresenta em sua composição uma porcentagem significativa de minerais. O teor de resíduo mineral pode ser considerado como medida geral de qualidade nos alimentos de acordo com Zheng e Wang (2003), pois quanto maior o teor de cinzas maior será os teores de cálcio, fósforo, magnésio, sódio, ferro e outros componentes minerais presente neste alimento. Em estudos encontrados na literatura os teores de cinza para a polpa da amora obtidos foram de 0,20\%, 0,15\% e 0,50\% (ANTONIO et al. 2009; LAMEIRO et al. 2011; IMRAN et al. 2010). Comparando o resultado obtido no presente trabalho com os valores de resíduo mineral para a polpa é perceptível que a folha da amoreira apresenta valores mais elevados de minerais, aproximadamente 18 vezes maior, fornecendo uma complementação significativa na dieta.

Os valores encontrados na literatura para cinzas presente nas folhas de Goiabeira (Psidiumguajava L.), Sabugueiro (Sambucus australis Cham. \& Schlecht.), Mostarda (Brassica integrigolia O. E. Schulz) e Alecrim-pimenta (Lippia sidoides Cham) foram 5,71\%, 9,75\%, 6,86\% e 8,97\%, respectivamente (ALMEIDA et al., 2003). Relacionando estes resultados com a folha de amora (TABELA 1) observamos a semelhança com a folha analisada e o rico valor nutricional das mesmas. Comparando a folha de amora com a de 
outras plantas com fins medicinais como Cajá-umbu (Spondias aff. tuberosa), Alfavaca (Ocimum gratissimum L.), Eucalipto (Eucalyptus tereticornis Smith), Maracujá (Passiflora edulis Sims.), Quebra-pedra (Phyllanthus amorus Schum. Et Thorn.), e Torém (Cecropia sp.), observa-se que a mesma apresenta teor de componentes minerais relativamente próximo ao das folhas citadas, sendo superior que as folhas de Cajá-umbu, Quebra-pedra e Torém (ALMEIDA et al., 2003).

A análise de cor apresentou as médias 14,4, 1,3, -0,5 para os parâmetros $\mathrm{L}^{*}, \mathrm{a}^{*}$ e b*, respectivamente (TABELA 1). Esses valores dizem a respeito da coloração da folha de amora que é verde, o que corrobora com o resultado do parâmetro a*, que apresentou resultado negativo.

Polifenóis são um tipo de fitoquímicos encontrados nos frutos, que são provenientes de diferentes partes das plantas como sementes, folhas e raízes (SKERGET et al., 2005; BLASA et al., 2010). Esses compostos apresentam diversos benefícios a saúde, colaboram com a qualidade organoléptica e da coloração, sendo os chás uma das principais fontes de polifenóis (MANACH et al., 2004). A coloração das folhas é alterada de acordo com o grau de maturação, devido à degradação da clorofila e aparecimento de novos pigmentos, como os carotenóides (KOBLITZ, 2008).

O teor de lipídeos encontrado na amostra de folha de amora foi de 5,36 $\pm 0,59 \%$ (TABELA 1) que não é um valor alto e que se situa entre os valores médios obtidos por Pinto et al. (2000) e Pereira et al. (2003) para folhas de taioba e de cenoura, respectivamente, sendo estes entre 6,00 e 7,06 \% para taioba e 2,5\% para as folhas de cenoura. A porcentagem lipídica encontrada nas folhas confere proteção à folha, servindo como uma barreira contra ação de agentes externos, além na auxiliar contra percas devido às reações da mesma em decorrer do tempo (SHEPHERD et al., 1995; MENDGEN, 1996; BARNES \& CARDOSOVILHENA, 1996). O teor de lipídeos presente em um alimento influencia diretamente na sua pré-disposição a sofrer rancidez lipídica (QUÍMICA DE ALIMENTOS, 2007), sendo assim, é pouco provável que a folha de amora sofra esta reação.

Observou-se que a folha da amora apresenta $\mathrm{pH}$ próximo a neutralidade, sendo levemente ácido (TABELA 1). O pH influência diretamente no sabor dos alimentos (PEREIRA et al., 2016). Com o resultado obtido na caracterização das folhas de amora podemos induzir que as mesmas apresentam sabor moderadamente amargo. O percentual de hidrogênio tem relação com o crescimento de bactérias, a maioria delas se multiplicam dentro 
de variações de pH próximo a neutralidade, entre 6,5 e 7,5 (TORTORA et al., 2003). Com isto percebe-se que as folhas de amora estão propensas ao desenvolvimento bacteriano, devido apresentarem seu $\mathrm{pH}$ na faixa de maior crescimento de bactérias.

O resultado obtido no presente estudo obteve como média para umidade 77,25\% (TABELA 1). É esperado que as folhas de amora apresentassem um alto teor de água na sua composição, devido ao fato delas representarem o componente da planta que possui o maior conteúdo de umidade, e também é nesta parte da planta onde ocorrem as maiores perdas de água pela transpiração (AWAD \& CASTRO, 1992). Analisando Capim-cidreira Leal et al. (2003) obteve valores para umidade de 69,6\% e Nogueira et al. (1996) adquiriu teores de umidade que variam na faixa de $66,57 \%$ a $91,02 \%$, ao estudar dez plantas medicinais.

A quantidade de SST encontrada na folha da amora apresentou valor médio de 2,8 ${ }^{\circ}$ Brix (TABELA 1). A análise de sólidos solúveis totais também contabiliza alguns ácidos orgânicos que estão no suco celular, de forma dispersa (PEREIRA et al., 2016). Como o valor obtido não é alto (TABELA 1) compreende-se que as folhas não apresentam grande quantidade desses ácidos e de açúcares solúveis, o que leva a amostra a possuir um baixo grau de doçura.

A folha da amora é rica em água e possui um teor de minerais satisfatório, trazendo benefícios à saúde, se consumida adequadamente. A mesma apresenta teores superiores ao da sua polpa de minerais, podendo ser considerada melhor no contexto de nutrição alimentar. Esta folha apresenta sabor com baixa doçura, constatado pelo valor de $\mathrm{pH}$ e pelo seu teor de sólidos solúveis totais. A concentração de açúcares redutores presente na folha da amora é baixa sendo considerada benéfica para saúde, abrangendo assim um público maior, tendo em vista que a população está cada vez mais preocupada com a saúde, e buscando cada vez mais ter uma alimentação saudável. A folha apresenta baixo teor de lipídeos em sua composição, não estando propensa a sofrer rancidez lipídica.

\section{Conclusões}

Com base na caracterização realizada no presente trabalho é possível concluir que a folha de amora pode ser utilizada como ingrediente para produção de novos alimentos, podendo ser adicionada em algum produto já existente, enriquecendo nutricionalmente o alimento. É uma forma de inovar e aproveitar uma parte pouco consumida pela população, tendo em vista que a folha da amora, normalmente é descartada e traz inúmeros benefícios a 
saúde, sendo também uma forma de colaborar com o meio ambiente, evitando desperdício e dando um novo destino a esta parte da planta.

\section{Referências}

ARGANDONA, E. J. S, MALDONADE, I. R., BREDA, C. A; ALVES, A. V., SILVA, T. G. Roteiro de Aulas Práticas da Disciplina de Análise de Alimentos. 1. Ed. Dourados: Editora da UFGD (EdUFGD), p.105, 2017.

ALMEIDA, M. M. B., LOPES, M. F. G., SOUSA, P. H. M., NOGUEIRA, C. M. D., ALMMORÄES, C. E. C. Determinação de umidade, fibras, lipídios, cinzas e sílica em plantas medicinais. Boletim do Centro de Processamento de Alimentos, v.21, n.2, p.343-350, 2003.

ANTONIO, G. C., FARIA, F. R., TAKEITI, C. Y., PARK, K. J. Rheological behavior of blueberry. Ciência e Tecnologia de Alimentos, v.29, n.4, p.732-737, 2009.

ANTUNES, L.E.C. Amora- Preta: Nova opção de cultivo no Brasil. Ciências Rural, v.32, p.151- 158, 2002.

AWAD, M.; CASTRO, P.R.C. Introdução à fisiologia vegetal. São Paulo: Nobel, p. 177 1992.

BARNES, J.D.; CARDOSO-VILHENA, J. Interactions between eletromagnetic radiation and cuticle.In: KERSTIENS, G. (Ed.). Plant cuticles: an integrated functional approach. Lancaster: Bios Scientific Publishers, p. 157-174, 1996.

BLASA, M., GENNARI, L., ANGELINO, D., NINFALI, P. Fruit and Vegetable Antioxidants in Health. In: Bioactive Foods in Promoting Health: Fruits and Vegetables. Ed. by Preedy, R. - Academic Press: United States of America. p. 37-43, 2010.

DAMIANI, C.; ALMEIDA, A. C. S.; FERREIRA, J.; ASQUIERI, E. R.; VILAS BOAS, E. V. B.; SILVA. F. A. Doces de corte formulados com casca manga. Pesquisa Agropecuária Tropical, Goiânia, v. 41, n. 3, p.360-369, 2011.

EMBRAPA (EMPRESA BRASILEIRA DE PESUISA AGROPECUÁRIA). O papel dos bancos de alimentos na redução do desperdício de alimentos. Set, 2009. Disponível em: www.badesc.gov.br/espaço. Acesso em: 10 de dez. de 2018.

ERCISLI, S.; ORHAN, E. Chemical composition of white (Morus alba), red (Morus rubra) and black (Morus nigra) mulberry fruits. Food Chemistry, v.103, p.1380-1384, 2007.

FREIRE, P. C. M., MANCINI-FILHO, J., FERREIRA, T. A. P. C. Principais alterações físico-químicas em óleos e gorduras submetidos ao processo de fritura por imersão: regulamentação e efeitos na saúde. Revista de Nutrição, v.26, n. 3, Campinas, Maio/Junho, 2013. 
HARDER MNC. Efeito do urucum (Bixa orellana L.) na alteração de característica de ovos de galinha poedeiras. p. 74, Dissertação de Mestrado. ESALQ/USP, Brasil, 2005.

IMRAN, M., KHAN, H., SHAH, M., KHAN, R., KHAN, F. Chemical composition and antioxidant activity of certain Morus species. Journal of Zhejiang Univ-Sci B (Biomed \& Biotechnol), v. 11, n. 12, p. 973-980, 2010.

INSTITUTO ADOLFO LUTZ. Métodos físico-químicos para análise de alimentos. Coordenadores Odair Zenebon, Neus Sadocco Pascuet e Paulo Tiglea. 4. ed. São Paulo: Instituto Adolfo Lutz, $1^{\mathrm{a}}$ edição digital, 2008.

KOBLITZ, M. G. B. (Coord.). Bioquímica de alimentos: teoria e aplicações práticas. Rio de Janeiro, RJ: GEN, 2008.

LAMEIRO, M.; MACHADO, M. I.; HELBIG, E.; ZAMBIAZI, R. Características físicoquímicas das polpas de amora-preta (rubus spp.) e de mirtilo (Vaccinium ashei reade). XIII ENPOS, 2011.

LEAL, T.C.A.B.; FREITAS, S.P.; SILVA, J.F.; CARVALHO, A.J.C. Produção de biomassa e óleo essencial em plantas de capim cidreira [Cymbopogon citratus (D.C.) Stapf.] em diferentes idades. Revista Brasileira de Plantas Medicinais, Botucatu, v.5, n.2, p.61-64, abril 2003.

MANACH, C., SCALBERT, A., MORAND, C., RÉMÉSY, C., JIMÉNEZ, L. Polyphenols: food sources and bioavailability. The American Journal of Clinical Nutrition, 2004.

MENDGEN, K. Fungal attachment and penetration. In: KERSTIENS, G. (Ed.). Plant cuticles: an integrated functional approach. Lancaster: Bios Scientific Publishers, p.175-188, 1996.

NOGUEIRA, C.M.D.; MORAIS, N.M.T.; LOPES, M.F.G.; SÁ, M.J.H.C. Análises químicas em plantas medicinais. Revista Brasileira de Farmácia, Rio de Janeiro, v.77, n. 1, p. 5-6, 1996.

PEREIRA, E. M.; LEITE, D. D. F.; FIDELIS, V. R. L.; PORTO, R. M.; OLIVEIRA, M. I. V.; MAGALHAES, W. B. Caracterização físico-química de hortaliças tipo folha comercializadas no Brejo Paraibano. Revista Agropecuária Técnica, Paraíba, v.37, n. 1, p. $19-22,2016$

PEREIRA, G. I. S., PEREIRA, R. G. F. A., BARCELOS, M. F; PÍCCOLO, \& MORAIS, A. R. Avaliação química da folha de cenoura visando ao seu aproveitamento na alimentação humana. Ciência e Agrotecnologia, p. 852-857, 2003.

PINTO, N. A. V. D.; CARVALHO, V. D. de; BOTELHO, V. A. V. A.; MORAES, A. R. de. Determinacion del potencial de Fibras dieteticas en las hojas de taioba (Xanthosoma sagittifolium Schott). Revista Alimentaria, Madrid, v.5, n.312, p.87-90, maio, 2000.

RIBEIRO, E. P., SERAVALLI, E. A. G. Química de Alimentos, ed. Edgard Blücher Ltda, p. $129,2007$. 
ROCHA, S.A. et al. Fibras e lipídios em alimentos vegetais oriundos do cultivo orgânico e convencional. Revista SimbioLogias, v.1, n.2, p.1-9, 2008.

SHEPHERD, T.; ROBERTSON, G.W.; GRIFFITHS, D.W.; BIRCH, A.N.E.; DUNCAN, G. Effects of environment on the composition of epicuticular wax from kale and swede. Phytochemistry, v.40, p.407-417, 1995.

SILVA, M. B; RAMOS, A. M. Composição química, textura e aceitação sensorial de doces em massa elaborados com polpa de banana e banana integral. Revista Ceres, Viçosa, v. 56, n.5, p. 551-554, 2009.

SKERGET, M., KOTNIK, P., HADOLIN, M., HRAS, A., SIMONIC, M., KNEZ, Z. Phenols, proanthocyanidins, flavones and flavonols in some plant materials and their antioxidant activities. Food Chemistry, p.:191-198, 2005.

TAKAYANAGI, T. \& YOKOTSUKA, K. Relationship between sucrose accumulation and sucrose-metabolizng enzymes in developing grapes. American Journal of Enology and Viticulture. Davis, v. 48, n. 4, p. 403-407, 1997.

TERRA, N. N.; FREITAS R. J. S.; CICHOSKI A. J. Atividade de água, pH, umidade e desenvolvimento de Staphylococcus xylosus durante o processamento e armazenamento da paleta suína curada, maturada e fermentada. Ciência Tecnologia de Alimentos, Campinas, v. 27, n. 4, p. 756-760, out. - dez. 2007.

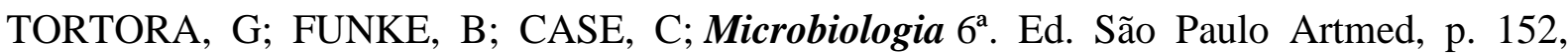
2003.

VALENÇA, R. S. F.; SANTANA, M. F. S. de; FREITAS, M. M. de. Aproveitamento da casca de bacuri para elaboração de biscoitos. In: VI SEMINÁRIO DE INICIAÇÃO CIENTÍFICA DA UFRA E XII SEMINÁRIO DE INICIAÇÃO CIENTÍFICA DA EMBRAPA AMAZÔNIA ORIENTAL, 2008.

VIZZOTO, M. Amora-preta: uma fruta antioxidante. Artigo de Divulgação na Mídia Embrapa Clima Temperado, 2008.

ZHENG, W.; WANG, S. Y. Oxygen radical absorbing capacity of phenolics in blueberries, cranberries, chokeberries, and lingonberries. Journal of Agricultural and Food Chemistry, 